\title{
Effect of grit on performance in Crossfit in advanced and novice athletes
}

\author{
(i) Michael Cazayoux, (iD Mark DeBeliso \\ Department of Kinesiology and Outdoor Recreation, Southern Utah University, Cedar City, UT, USA
}

\begin{abstract}
Sport performance is affected by physical as well psychological traits. The psychological trait grit has been shown to effect athletic performance. This study attempted to identify the level of grit in novice and advanced Crossfit athletes in order to determine if levels of grit play a role related to performance in the sport of fitness known as Crossfit. Male and female Crossfit athletes $(\mathrm{n}=50)$ completed the 12-Point Grit Scale test. The 12-Point Grit Scale is a 12-question instrument with two subscales (Perseverance of Effort, PE; Consistency of Interest, CI). The subscale scores and total grit scale scores were compared between the novice and advanced Crossfit athletes with independent t-tests $(\alpha \leq 0.05)$. The advanced Crossfit athletes $(n=23)$ scored significantly greater than the novice athletes $(n=27)$ for both the 12Item Grit scale as well as the CI subscale $(\mathrm{p}<0.05)$. There was not a statistical difference in the PE subscale scores between the novice and advanced Crossfit athletes $(\mathrm{p}<0.05)$. As hypothesized, this study found grit levels to be greater among advanced Crossfit athletes suggesting that grit may play a role in successful participation in the sport of fitness known as Crossfit. Athletes and coaches could use this information in the training environment in a way that maximizes an athlete's level of grit in order to get a competitive edge. Athletes and coaches could implement the findings of the current study by understanding the importance of practice, finding purpose in why they train in the first place, developing a sense of hope, and joining an existing gritty group of athletes.
\end{abstract}

Keywords. Crossfit, grit, sport of fitness.

\section{Introduction}

Optimizing athletic performance has been one of the greatest human pursuits for thousands of years. Ever since human beings started playing and competing in sports, they started to look for an edge over their competitors. Over the years researchers have looked at a number of physical characteristics that separate athletes including technical ability (Coelho e Silva et al., 2010; Figueiredo et al., 2009; le Moal et al., 2013) and physical fitness (Deprez et al., 2015; le Gall et al., 2010). While the physical aspect of sport has gained the most attention, the psychological component also plays a huge role.

The 1920s saw the dawn of the field of sport psychology in Germany (Cole, 2012). Since then researchers have studied psychological characteristics and their relationship to performance in sport (Baker \& Côté, 2003; Duckworth et al., 2007; Guelmami et al., 2014; Reilly et al., 2000) such as early and enduring passion (Gulbin et al., 2010), conscientiousness (Piedmont et al., 1999), selfcontrol (Toering \& Jordet, 2015), perceptualcognitive skills (Ward et al., 2013; Ward \& Williams, 2003; Williams et al., 2006), and sport-specific engagement (Ford et al., 2012; Roca et al., 2012). Comparing qualifiers to non-qualifiers in the 1980 US Olympic Trials Silva et al. (1985) even suggested that psychological factors play a bigger role than

Received: January 25, 2019 - Accepted: February 27, 2019 - Published: March 30, 2019

To cite this article: Cazayoux M, DeBeliso M. Effect of grit on performance in Crossfit in advanced and novice athletes. Turk J Kinesiol, 2019; 5(1): 28-35.

$\triangle$ M. DeBeliso, e-mail: markdebeliso@suu.edu

DOI: 10.31459/turkjkin.517615 
physical attributes at the highest level of competition.

One of these psychological variables, grit, has recently gained mainstream popularity. According to Duckworth et al. (2007), grit consists of "working strenuously towards challenges, maintaining effort and interest over years despite failure, adversity, and plateaus in progress". Grit is further defined as perseverance and passion towards long term goals. Grit predisposes individuals to commit to a discipline for a long period of time in spite of psychological factors and conflicting goals. Less gritty individuals are more likely to allow momentary failures or new goals to deter them from continued pursuit of a discipline. The two factors that make up grit are perseverance of effort (PE; one's ability to sustain effort in the face of adversity) and consistency of interest $(\mathrm{CI}$; the tendency to remain interested in the same goal-pursuits over time) (Duckworth et al., 2007).

There is much evidence supporting grit as a necessary construct as related to successful performance in a variety of fields. Duckworth et al. (2007) showed that grit was associated with the retention of West Point Academy cadets, ranking in the children's National Spelling Bee and educational attainment of adults. However, there has been little research to date on the effect of grit on sport performance.

In exercise psychology, grit was linked to intensity of exercise (Reed et al., 2013). Larkin et al., (2016) found that gritty youth male soccer players performed better than less gritty players on measures of sport specific cognition and deliberate sport specific practice. The largest and most recent study of grit related to sport performance was done by Tedesqui \& Young (2017). They found that the component of the construct of grit, PE, was significantly correlated with the highest-level skill groups. They also found that PE was correlated with athletes' amounts of deliberate practice regardless of whether it was mandatory or optional. The same study found that the other component of the construct of grit, CI, was inversely correlated with the frequency of thinking about switching or quitting one's main sport. On the other hand, not all research supports the importance of grit. Joseph (2009) found no correlation on self-reported surveys between grit and athletic performance in female collegiate volleyball players. Given the rapid growth in the popularity of Crossfit and fitness competitions, coaches and athletes might be interested in the importance of grit in the sport.

Since being incorporated in 2000, Crossfit has become one of the most popular fitness programs on the planet (Rische, 2011). Defined as "constantly varied functional movements performed at high intensity" (Butcher et al., 2015), Crossfit has transformed the worldwide fitness industry making functional fitness and general physical preparedness a mainstream method for people to attain peak levels of physical conditioning.

According to www.Crossfit.com, in 2007, Crossfit introduced "The Crossfit Games" to a group of 70 athletes at a ranch in Aromas, California, United States. Since that time, the Crossfit Games has experienced exponential growth with over 380,000 athletes registering for the 2017 Crossfit Open. The Crossfit Open is now the first stage of the three stage Crossfit Games season. To further exemplify the rapid growth of the sport, the total prize purse grew from $\$ 25,000$ in 2010 to $\$ 1$ million in 2011 and has risen to $\$ 2.2$ million in 2017. Largely responsible for this growth and cult-like community in Crossfit is the inclusivity of participation (Dawson, 2017). In an everyday Crossfit class, it would be typical to see a mother of three, a firefighter, a nurse, an advanced athlete and someone over the age of 60 working out alongside one another.

Crossfit programs are intended to develop competence in 10 fitness domains, including accuracy, agility, balance, coordination, cardiovascular and respiratory endurance, flexibility, power, speed, stamina, and strength (Gerhart, 2013). To be competitive in the sport of Crossfit, an athlete must develop competency in the 
sports of weightlifting, gymnastics, speed and agility, endurance and strongman style activities. While an athlete's physical characteristics are of the utmost importance in the sport of Crossfit, psychological traits are likely to play a significant role as well. Gould et al. (2002) revealed that elite athletes have higher self-confidence, concentration, arousal control, motivation, and commitment, and these characteristics are likely to be important factors in Crossfit Games performance. Likewise, grit (PE and $\mathrm{CI}$ ) could be important constructs as related to high achievement in Crossfit Games.

Hence the purpose of this study was to compare the construct of grit between novice and advanced Crossfit athletes. The research hypotheses being that grit, as assessed by the12-Item Grit Scale (Duckworth, et al., 2007) will be higher in advanced Crossfit Games athletes compared to novice Crossfit athletes.

\section{Methods}

\section{Participants}

Potential participants ranged from novice to advanced Crossfit athletes. Athletes that had never made it past the CrossFit Open or first stage of Crossfit competition were considered to be novice in development. These novice athletes were contacted regarding participation in the study through a Crossfit gym in Texas, USA. Athletes that had reached and competed at the final stage of Crossfit competition, the Crossfit Games, were considered to be advanced in their development. The advanced athletes were contacted regarding participation in the study through email and text message by the lead investigator. The advanced group of athletes lived in US, Canada, and Australia. All athletes (male and female) had a range of experience from 6 months to 10 years. The study was reviewed and approved (including informed consent) by a University Institutional Review Board for the ethical use of humans in research.

\section{Instrument}

Duckworth et al. (2007) developed the 12-point Grit Scale in order to assess grit and the associated constructs of PE and CI. Of the 12 questions, there are 6 questions that asses $\mathrm{PE}$ and 6 questions that assess CI all on a 1-5 Likert scale. PE is assessed in questions $(2,3,5,7,8,11)$ on the survey while $\mathrm{CI}$ is assessed in questions $(1,4,6,9,10,12)$. After completion of the survey, the sum of all 12 questions is divided by 12 to provide an overall grit score with 5 being the maximum score (i.e. Extremely gritty) and 1 being the lowest score (i.e. not at all gritty).

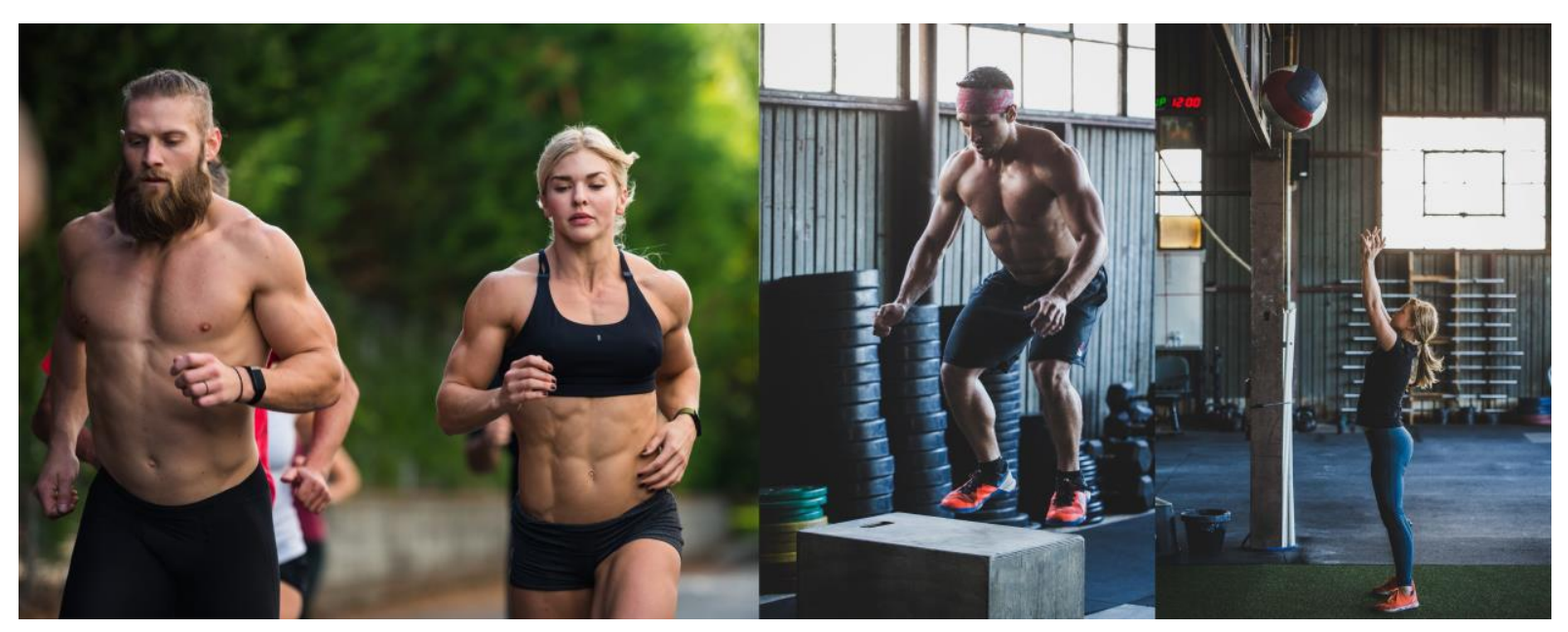

Figure 1. Crossfit the "sport of fitness" (pictures courtesy of M. Cazayoux). 
However, the analysis in the current study did not normalize the scores to the 5-point Likert scale in order to establish a more precise analysis of the 12point Grit Scale and associated subscales. The internal consistency of the 12-point Grit and subscales has been reported to range from $\alpha=0.68$ 0.78 (Duckworth et al., 2007). The test re-test (stability reliability) of the 12-point Grit and subscales has been reported to range from ICC $=0.76$ 0.91 (Cazayoux et al., 2018).

\section{Procedures}

Athletes $(n=85)$ were all recruited through personal contact by either email or text message. Total recruitment time was 4 weeks. Interested athletes were then emailed a link to SurveyMonkey.com where the 12-point Grit Scale was administered. Survey Monkey is a website platform (SurveyMonkey.com) that allows users to take a survey online and also stores the results. The athletes were sent the survey and were allowed 3 weeks to respond. The athletes were required to provide a separate informed consent as a requisite to completing the 12-point Grit Scale. Figure 2 provides a summary of the study events. All data was entered into an MS Excel spreadsheet for statistical analysis after all surveys were complete.

\section{Statistical analysis}

The dependent variables (DVs) in this study were the scores on the 12-point Grit scale and the PE and CI subscales. The DVs were compared between novice and advanced Crossfit athletes with independent t-tests. Statistical significance was set at $\mathrm{p}<0.05$. However, given the recent concerns regarding reproducibility of research results and the over reliance upon "p-values" to assess the results of research outcomes (Amrhein et al., 2017), effect size calculations were also included in the analysis. Data management and statistical analysis were conducted with Microsoft Excel (2013). The raw data was peer reviewed for accuracy prior to statistical analysis as suggested by AlTarawneh \& Thorne (2017).

\section{Results}

Novice Crossfit athletes $(n=27)$ and advanced level Crossfit Games athletes $(n=23)$ participated in this study and completed the 12-Point Grit scale. Table 1 provides mean participant scores on the 12-Item Grit Scale as well as mean scores on both PE and CI.

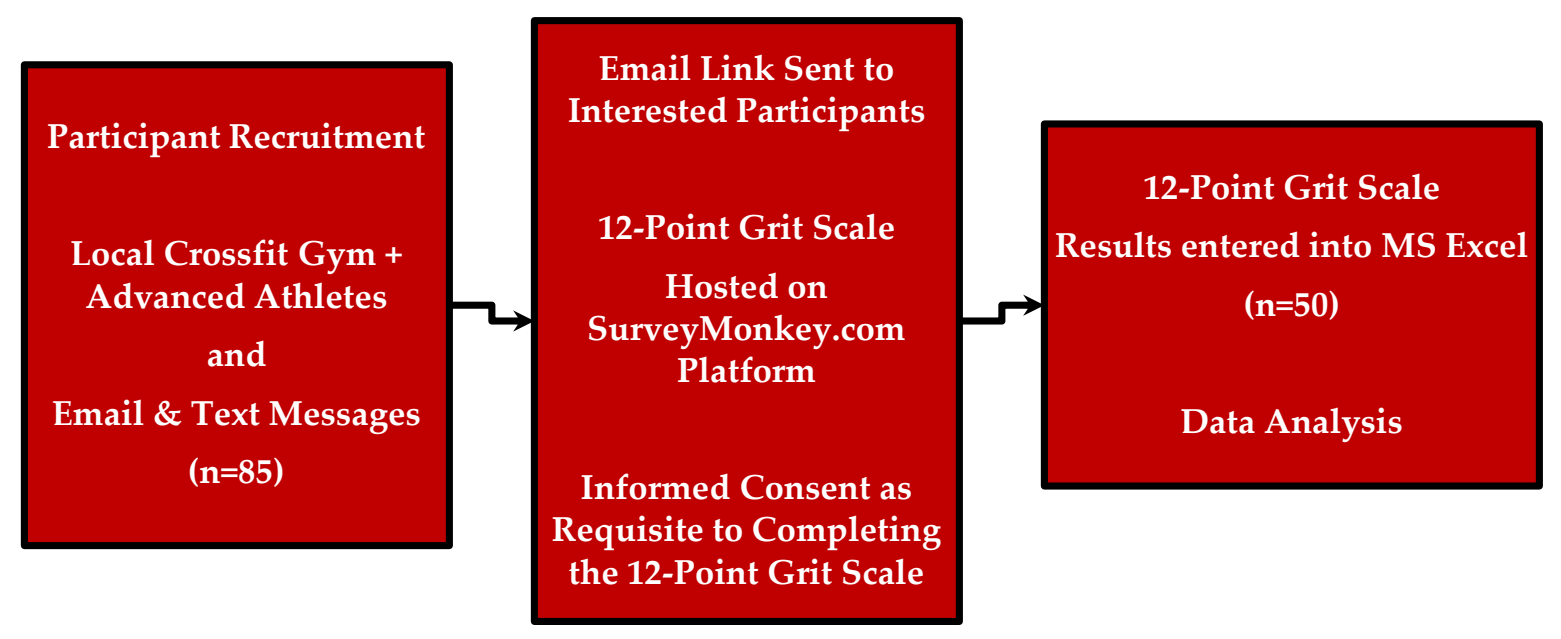

Figure 2. Time line of events and procedures. 
Table 1

Grit scale scores.

\begin{tabular}{lcccc}
\hline & $\mathrm{N}$ & $\begin{array}{c}\text { Total Score } \\
\text { 12-Item Grit Scale }\end{array}$ & Grit PE Score & Grit CI Score \\
\hline Novice & 27 & $48.1 \pm 5.3$ & $26.2 \pm 3.0$ & $21.9 \pm 3.3$ \\
Elite & 23 & $51.0 \pm 5.1$ & $27.1 \pm 2.3$ & $23.9 \pm 3.4$ \\
Effect Size & & 0.57 & 0.38 & 0.59 \\
p-value & $0.03^{*}$ & 0.13 & $0.02^{*}$ \\
\hline
\end{tabular}

Grit scale scores (mean \pm SD). PE-Perseverance of effort. CI-Consistency of interest. Effect size-standard deviations.

Significant differences in Grit scale scores between groups $(\mathrm{p}<0.05)$.

The advanced Crossfit athletes scored significantly greater than the novice athletes for both the 12-Item Grit scale as well as the CI subscale $(p<0.05)$. There was not a statistical difference in the PE subscale scores between the novice and advanced Crossfit athletes $(p=0.13)$. The ES differences between the novice and advanced Crossfit athletes ranged from ES=0.57-0.59 for the 12-Item Grit scale and CI subscale scores respectively, both considered as moderate (Cohen, 1988).

\section{Discussion}

The purpose of this study was to identify the level of grit in novice and advanced Crossfit athletes in order to determine if levels of grit play a role related to performance in the sport of fitness known as Crossfit as measured by the 12-point Grit Scale. Consistent with our research hypothesis, the advanced Crossfit athletes scored significantly higher than the novice athletes for both the 12-Item Grit scale as well as the CI subscale. Contrary to our research hypothesis there was no statistical difference in PE between advanced Crossfit and novice athletes.

As expected, these results support and extend the findings of research within different sports, modes of exercise and among other types of athletes and populations as to the importance of grit and it's subscales for achievement outcomes. The current study supports the findings of Larkin et al. (2015) who found that gritty players performed better on assessments of decision-making and situational probability as well as accumulated significantly more time in sport-specific activities. The current study also extends the research of Reed et al. (2013) who found grit significantly predicted what behavioral stage the participants were in with regards to moderate to high intensity exercise. Finally this study furthers the research of Duckworth et al. (2007) who found that grit accounted for successful outcomes in the retention of West Point Academy cadets, ranking in the children's National Spelling Bee and educational attainment of adults. The results of the current study are salient in that it furthers the notion that grit is an important characteristic in athletic performance.

While we found significant group differences in grit levels, the main sub-scale for the difference in the two groups (novice and advanced participants) was CI, which is at odds with other relevant studies. Credé et al. (2016) and Tedesqui \& Young (2017) both demonstrated PE to be the more important factor of the two grit subscales. However, this contrary result does support the essential need to quantify the two sub-scales in future studies. A possible explanation for the discrepancy in findings follows.

Duckworth et al. (2007) likened CI to the direction of one's pursuit of goals and PE to the duration of that pursuit. Interest in Crossfit as a means to maintaining a general level of fitness is different than interest in team and individual sports as was the case in Tedesqui \& Young (2017). The athletes within our two groups may have very different goals. The vast majority of novice Crossfit athletes use it as a means to stay fit, while those competing at the advanced level treat it as a profession or 
devotion almost without exception. By choice, many of these advanced athletes have little to no work outside their pursuit of athletic performance. This is often their means of general fitness, a competitive pursuit, and even their means of financial security. Athletes in the novice group likely have hobbies and pursuits outside of the Crossfit classes they attend, not to mention careers outside of the sport of fitness. Hence it is possible that we measured the $\mathrm{CI}$ or direction of the pursuit of different goals in our two groups.

According to www.Crossfit.com, there is a popular adage by Crossfit founder Greg Glassman that "The needs of Olympic athletes and our grandparents differ by degree, not kind." As such, it is common even for novice Crossfit athletes to perform at an extremely high level of relative intensity for one hour per day several days per week. Both groups are aiming for an increased level of fitness, but the novice athletes may be pursuing it as a means of improving or maintaining general fitness while the advanced athletes may be pursuing it as a competitive career. So it may be that both the advanced and novice athletes have a similar level of $\mathrm{PE}$ in the pursuit of different goals. If the primary goal of the novice athletes was to compete in the sport of fitness, it would be reasonable to expect results consistent with those of relevant studies such as Tedesqui \& Young (2017) who found PE to accurately predict advanced and elite skill levels among swimmers, hockey players and soccer players.

One limitation of this study is that athletes did not report their age, and research shows that we generally get grittier as we get older (Duckworth et al., 2007). The average age of advanced level Crossfit athletes is 27 for males and 28 for females (Crossfit Games Athletes, 2018), and 35\% of general Crossfit athletes are over age 34. ("The Business of Crossfit an Update on New Market Research", 2017). Hence, it is possible that there may have been age group differences in the novice and advanced Crossfit athletes. If the current study had controlled for age, additional and/or greater differences in grit between novice and advanced Crossfit athletes may have been detected.

Next, geography is a limitation in this study. Advanced athletes were from the United States, Canada and Australia while the group of novice athletes was comprised entirely from individuals living in the same city in Texas (USA). Finally, the sample size in this study $(n=50)$ may not have been adequate to fully represent novice and advanced Crossfit athletes with regard to grit.

Overall our findings support the role of grit in athletic achievement. Total grit scores as well as CI were related to the level of participant skill level. Thus, this study furthers the research of Duckworth et al. (2007) and Tedesqui \& Young (2017) on the role of grit in achievement in sport. It also furthers the conclusions of Tedesqui \& Young and Credé et al. (2016) that demonstrated the need to study the two constructs of grit, CI and PE, separately. Future research should first ensure that age is controlled for. It may also be important for future researchers to have a larger sample size and study Crossfit athletes in a number of different geographical locations. Although we explored the relationship between grit and skill level in Crossfit, we did not explore its relationship to key aspects of advanced skill development such as amounts of deliberate practice (Baker \& Young, 2014). As suggested by Tedesqui \& Young (2017), future researchers might explore the relationship between grit and deliberate practice in sport. Finally, future research might examine potential gender differences with regards to grit and Crossfit participation.

\section{Conclusions}

In sum, our findings support other research pointing to the predictive validity of grit on athletic skill level. The results of the current study found differences between novice and advanced Crossfit athletes in both total grit scores as well as levels of CI. Conversely, the PE scores were not significantly difference between novice and advanced Crossfit 
athletes. These findings suggest that grit, and specifically the consistency of an athlete's interest in a given sport may lead to higher levels of performance. Crossfit athletes looking to compete at the Crossfit Games might intentionally use CI, or the ability to stay focused on one goal, as a competitive advantage.

\section{Conflict of interest declaration}

No funding was received for this research. The authors have no conflict of interest related to this research.

\section{References}

Baker J, Cote J, Abernethy B. Sport-specific practice and the development of expert decision-making in team ball sports. Journal of Applied Sport Psychology, 2003; 15(1): 12-25.

Baker J, Côté J. Resources and commitment as critical factors in the development of 'Gifted' athletes. High Ability Studies, 2003; 14: 139-140. doi:10.1080/1359813032000163816

Butcher SJ, Neyedly TJ, Horvey KJ, Benko CR. Do physiological measures predict selected $\mathrm{CrossFit} \AA$ benchmark performance? Open Access Journal of Sports Medicine, 2015; 6: 241.

Cazayoux M, Bishop A, Navalta J, Harris C, Adams KJ, DeBeliso M. The reliability of the 12-Item Grit scale among CrossFit participants. European Journal of Physical Education and Sport Science, 2018; 4(10): 1-10.

Coelho E Silva MJ, Figueiredo AJ, Simões F, Seabra A, Natal A, Vaeyens R, Philippaerts R, Cumming SP, Malina RM. Discrimination of U-14 soccer players by level and position. International Journal of Sports Medicine, 2010; 31(11): 790-796.

Cohen J. Statistical power analysis for the behavioural sciences, (2nd Ed.). Hillsdale. NJ: Lawrence Earlbaum Associates, 1988.

Cole B. Sport psychology: A short history and overview of a field whose time has come, and how it can help you in your sport. Retrieved May 18, 2018, from http://www.mentalgamecoach.com/articles/SportP sychology.html
Credé M, Tynan MC, Harms PD. Much ado about grit: A meta-analytic synthesis of the grit literature. Journal of Personality and Social Psychology, 2017; 113(3): 492.

CrossFit Games Athletes Older Than Ever Before. Retrieved November 16, 2018 from https://heatonminded.com/2018-crossfit-gamesathletes-older-than-ever-before/

CrossFit Games Prize Purse Grows. July 7, 2014. Retrieved May 18, 2018, from https://games.crossfit.com/article/crossfit-gamesprize-purse-grows

Deprez D, Fransen J, Boone J, Lenoir M, Philippaerts R, Vaeyens R. Characteristics of high-level youth soccer players: variation by playing position. Journal of Sports Sciences, 2015; 33(3): 243-254.

Duckworth AL, Peterson C, Matthews MD, Kelly DR. Grit: perseverance and passion for long-term goals. Journal of Personality and Social Psychology, 2007; 92(6): 1087.

Figueiredo AJ, Gonçalves CE, Coelho e Silva MJ, Malina RM. Characteristics of youth soccer players who drop out, persist or move up. Journal of Sports Sciences, 2009; 27(9): 883-891.

Finding the Fittest on Earth. (n.d.). Retrieved May 18, 2018, from https://games.crossfit.com/history-ofthe-games

Ford P, Carling C, Garces M, Marques M, Miguel C, Farrant A, Stenling A, Moreno J, Le Gall F, Holmström S, Salmela JH, Williams AM. The developmental activities of elite soccer players aged under-16 years from Brazil, England, France, Ghana, Mexico, Portugal and Sweden. Journal of Sport Sciences, 2012; 30(15): 1653-1663.

Gerhart HD. A comparison of Crossfit training to traditional anaerobic resistance training in terms of selected fitness domains representative of overall athletic performance. Master Theses, Indiana University of Pennsylvania, 2013. http://knowledge.library.iup.edu/etd/1175

Gould D, Dieffenbach K, Moffett A. Psychological characteristics and their development in Olympic champions. Journal of Applied Sport Psychology, 2002; 14(3): 172-204. 
Guelmami N, Hamrouni S, Agrébi B. Psychological profiles of talented male youth athletes in team sports games. Journal of Physical Education and Sport Management, 2014; 5(1): 5-10.

Gulbin JP, Oldenziel KE, Weissensteiner JR, Gagne F. A look through the rear-view mirror: Developmental experiences and insights of high performance athletes. Talent Development and Excellence, 2010; 2(2): 149-164.

Joseph AI. The role of grit in predicting performance in collegiate athletes. Doctoral dissertation, 2009. Retrieved from ProQuest Information \& Learning, May 18, 2018.

Larkin P, O'Connor D, Williams AM. Does grit influence sport-specific engagement and perceptualcognitive expertise in elite youth soccer? Journal of Applied Sport Psychology, 2016; 28(2): 129-138.

le Gall F, Carling C, Williams M, Reilly T. Anthropometric and fitness characteristics of international, professional and amateur male graduate soccer players from an elite youth academy. Journal of Science and Medicine in Sport, 2010; 13(1): 90-95.

le Moal E, Rué O, Ajmol A, Abderrahman AB, Hammami MA, Ounis OB, Kebsi W, Zouhal H. Validation of the Loughborough soccer passing test in young soccer players. J Strength Cond Res, 2014; 28(5): 1418-1426.

Piedmont RL, Hill DC, Blanco S. Predicting athletic performance using the five-factor model of personality. Personality and Individual Differences, 1999; 27(4): 769-777.
Reed J, Pritschet BL, Cutton DM. Grit, conscientiousness, and the transtheoretical model of change for exercise behavior. Journal of Health Psychology, 2013; 18(5): 612-619.

Reilly T, Williams AM, Nevill A, Franks A. A multidisciplinary approach to talent identification in soccer. Journal of Sports Sciences, 2000; 18: 695702.

Roca A, Williams AM, Ford PR. Developmental activities and the acquisition of superior anticipation and decision making in soccer players. Journal of Sports Sciences, 2012; 30(15): 1643-1652.

Tedesqui RA, Young BW. Associations between selfcontrol, practice, and skill level in sport expertise development. Res Q Exerc Sport, 2017; 88(1): 108113.

Tedesqui RA, Young BW. Perspectives on active and inhibitive self-regulation relating to the deliberate practice activities of sport experts. Talent Development \& Excellence, 2015; 7(1): 29-39.

Toering T, Jordet G. Self-control in professional soccer players. J Appl Sport Psychol, 2015; 27(3): 335-350.

Ward P, Williams AM. Perceptual and cognitive skill development in soccer: The multidimensional nature of expert performance. Journal of Sport and Exercise Psychology, 2003; 25(1): 93-111.

What is CrossFit? (n.d.). Retrieved May 18, 2018, from https://www.crossfit.com/what-is-crossfit

Williams AM, Hodges NJ, North J, Barton G. Perceiving patterns of play in dynamic sport tasks: Investigating the essential information underlying skilled performance. Perception, 2006; 35: 317-332. 